\title{
Caractérisation des systèmes de culture intégrant le gombo dans le maraîchage urbain et périurbain de Bouaké dans le Centre de la Côte d'Ivoire
}

\author{
Lassina FONDIO ${ }^{1 *}$, Christophe KOUAME ${ }^{2}$, Andé Hortense DJIDJI ${ }^{1}$ et \\ Dossahoua TRAORE ${ }^{3}$ \\ ${ }^{1}$ Centre National de Recherche Agronomique/Station d'Anguédédou/Programme Cultures Maraîchères et \\ Protéagineuses, $01 \mathrm{Bp} 1740$ Abidjan 01 Côte d'Ivoire. \\ ${ }^{2}$ ICRAF, Abidjan, Côte d'Ivoire. \\ ${ }^{3}$ Université de Cocody-Abidjan/UFR Biosciences, 22 Bp 582 Abidjan 22 Côte d'Ivoire. \\ *Auteur Correspondant, E-mail : Ifondio@yahoo.fr
}

\section{RESUME}

Une étude a été conduite en 2001 auprès de 94 producteurs maraîchers dans la région de Bouaké, au Centre de la Côte d'Ivoire. Elle avait pour objectif de décrire les systèmes de culture intégrant le gombo dans le maraîchage urbain et périurbain de Bouaké en vue de ressortir les contraintes et de dégager des perspectives d'amélioration. Elle a consisté à interroger les producteurs sur leur identité, la place du gombo dans l'activité agricole, les techniques culturales du gombo, etc. Il est ressorti que le maraîchage est dominé par les hommes d'origine étrangère à la région (64\% d'allochtones contre 33\% d'autochtones) et implique diverses catégories socio-professionnelles. Le gombo est produit dans cinq principaux systèmes de culture: jardins de case, système de culture à base d'igname, système à base de céréales, système à base de cultures maraîchères et monoculture du gombo. L'insécurité foncière et le faible appui de la vulgarisation constitueraient les principaux obstacles à l'amélioration de la production du gombo dans la région. A cet effet, l'adoption d'une politique d'intégration de l'agriculture dans les plans d'aménagement urbain, le renforcement de la vulgarisation agricole et une recherche participative impliquant tous les acteurs (producteurs, vulgarisateurs et chercheurs) contribueraient à améliorer le rendement du gombo et du maraîchage dans la région de Bouaké.

(C) 2011 International Formulae Group. All rights reserved.

Mots clés : Gombo, systèmes de culture, Côte d'Ivoire.

\section{INTRODUCTION}

Avec 5,5 kilogrammes de fruits frais par habitant/an, le gombo vient en tête devant l'aubergine $(3,7 \mathrm{~kg} / \mathrm{habitant})$ et la tomate $(1,4$ $\mathrm{kg} / \mathrm{habitant})$, des légumes de grande consommation en Côte d'Ivoire (DSDI, 2005). Dans la Commune de Bouaké au Centre du pays, $41 \%$ de la population ont pour sauce préférée celle à base du gombo, contre $29 \%$ pour la sauce à base d'aubergine, $20 \%$ pour celle à base de tomate, et $10 \%$ pour les sauces à base d'autres légumes (Fondio, 2005). Pour toutes ces raisons, le gombo semble constituer un légume important pour les populations de la région de Bouaké dont leur approvisionnement est assuré principalement par les maraîchers installés dans et autour de la ville qui tirent leurs subsistances du maraîchage. A cet effet, Affou (1999) a soutenu que depuis 1990, avec la chute des 
cours des matières premières, qui a entraîné une crise économique dans le pays occasionnant des pertes d'emplois, le maraîchage est devenu une source de revenu et d'existence surtout pour les populations urbaines. Mais, les travaux de recherche sont peu abondants sur les systèmes de culture intégrant le gombo et ses itinéraires de productions dans ce maraîchage urbain et périurbain. En effet, en Côte d'Ivoire, les études sur ce secteur de l'agriculture urbaine et périurbaine semblent relativement récentes. Les programmes de recherche mis en place, avant 1960, se sont plutôt intéressés aux cultures de rente (café, cacao, palmier à huile, hévéa, etc.) pour leur rôle de pourvoyeur de revenu à l'économie nationale (Ahoussou et al., 1995). Ce n'est qu'en 1990 qu'un programme de recherche sur les cultures maraîchères et protéagineuses a été créé au sein de l'ex-Institut de Savanes (IDESSA) de Bouaké aujourd'hui intégré au Centre National de Recherche Agronomique. En conséquence, les systèmes de productions maraîchères ne sont pas suffisamment caractérisés pour dégager les contraintes et proposer des solutions pour améliorer la productivité du secteur. C'est dans ce contexte que cette étude a été réalisée en s'appuyant sur le cas du gombo pour contribuer à une meilleure connaissance du maraîchage dans les zones urbaines du pays. Elle avait donc pour objectif de caractériser les systèmes de culture intégrant le gombo dans le maraîchage urbain et périurbain de Bouaké pour ressortir les contraintes et dégager des perspectives d'amélioration. A partir d'une enquête sur le terrain, la typologie des producteurs, les systèmes de culture du gombo et les facteurs de production sont décrits.

\section{MATERIEL ET METHODES}

L'étude a été réalisée dans la région de Bouaké, entre Avril et Juin 2001. Bouaké est située au Centre du pays, à $7^{\circ} 46$ de Latitude Nord, $5^{\circ} 06$ de Longitude Ouest et à $376 \mathrm{~m}$ d'Altitude (Figure 1). Sur 173 maraîchers recensés en 2000 dans la Commune de Bouaké par l'Agence Nationale d'Appui au
Développement Rural (ANADER, 2001), 94 (soit 54,34\%) ont été interrogés au cours de l'enquête. Ils ont été choisis sur la base de la présence du gombo dans l'exploitation et l'acceptation de se soumettre au questionnaire. Celui-ci portait sur l'identification des producteurs (autochtones, allochtones, étrangers, âge, profession principale, etc.), les variétés de gombo cultivées, les systèmes de culture, les pratiques culturales, etc. Le dépouillement des résultats de l'enquête a été fait à l'aide du Logiciel CSTAT du CIRAD (Foucher, 1992) qui a consisté à faire une analyse factorielle des correspondances multiples (AFCM). Pour cela, les paramètres qualitatifs (sexe, nationalité, profession, pratiques culturales, etc.) ont été codifiés. Sur l'ensemble des données quantitatives (âge, nombre d'enfants, taille de l'exploitation, etc.) et qualitatives, un recodage a été effectué pour constituer des classes de modalités. Une illustration graphique par le Logiciel a alors permis d'obtenir les différents regroupements des producteurs, selon leurs caractères qualitatifs et quantitatifs.

\section{RESULTATS}

\section{Caractéristiques sociologiques des producteurs maraîchers}

Selon le Tableau 1, les maraîchers rencontrés dans la Commune de Bouaké se composent de $74 \%$ d'hommes et de $26 \%$ de femmes. Ils se répartissent en $33 \%$ d'autochtones, $64 \%$ d'allochtones et $3 \%$ d'étrangers. Les Baoulé originaires de la région de Bouaké constituent la population autochtone. Les Senoufo, les Tagbanan, les Djimini et les Malinké qui sont originaires des régions Nord du pays (Odienné, Korhogo, Ferkessédougou, etc.) forment les allochtones. Les populations étrangères viennent $\mathrm{du}$ Burkina-Faso, du Mali et du Togo. Les maraîchers interrogés sont âgés de 23 à 71 ans avec $64 \%$ ayant moins de 40 ans, $31 \%$ de 41 à 60 ans et $5 \%$ de 61 à 71 ans. Ils se regroupent en $53 \%$ de mariés (légalement ou coutumièrement) et $44 \%$ de célibataires ; $3 \%$ des personnes ont refusé de se prononcer sur 
leur situation matrimoniale. Le nombre d'enfants dans la famille varie entre 0 et 24 dont $47 \%$ des familles ont 0 à 5 enfants, $41 \%$, 6 à 10 et 12\%, 11 à 24. Les maraîchers sont en majorité des illettrés $(68 \%$ des personnes enquêtées ne savent ni lire, ni écrire), contre $18 \%$ de niveau primaire, $8 \%$ du niveau secondaire et $6 \%$ du niveau supérieur (étudiants). Parmi ces 94 maraîchers, 57\% vivent dans les quartiers périphériques (Tchèlèkro, N'dakro, Kotiakro), 40\% dans les villages environnants (Dohoun, Konkondékro, N'guessankro) et $3 \%$ dans le Centre ville (Dougouba, Sokoura et Odienné-Kourani). Ce sont en majorité des professionnels qui ne vivent que du maraîchage (65\%). Mais, de plus en plus, des salariés de la fonction publique ou du secteur privé (7\%), des travailleurs exerçant une profession libérale (mécaniciens, artisans) soit $22 \%$ et des étudiants $(6 \%)$ s'intéressent au maraîchage.

\section{Variétés de gombo cultivées}

Deux variétés de gombo sont couramment cultivées par les maraîchers de Bouaké : Tomi et Koto. La variété Tomi de l'espèce Abelmoschus caillei se caractérise par les fruits non côtelés et allongés (Figure 2). Elle est connue sur le marché sous le nom de «gombo Baoulé ». La variété Koto de l'espèce Abelmoschus esculentus présente des fruits côtelés et moins allongés que ceux de la variété Tomi (Figure 3). Elle est connue sur le marché sous le nom de «gombo Dioula ». Au plan écologique, A. caillei (variété Tomi) a pour habitat les zones pré-forestières et forestières d'Afrique de l'Ouest jusqu'au Cameroun, alors que A. esculentus (variété Koto) provient des zones de savanes subsahariennes (Stevels, 1990).

\section{Facteurs de production}

Tous les paysans rencontrés travaillent avec des moyens rudimentaires composés de dabas, d'arrosoirs, de pioches et de binettes. Il n'existe pas de structure de crédit pour financer la campagne agricole. Toutefois, il peut arriver que les producteurs contractent des dettes auprès des vendeuses, qu'ils remboursent à la récolte du gombo. Mais, ils trouvent que ces dettes ne leur sont pas profitables car, par exemple, pour 10000 FCFA $(15,24 €)$ empruntés ils rembourseront 12500 FCFA (19 €) et en plus, la prêteuse (commerçante) fixe le prix de vente. Les exploitations maraîchères sont de petites tailles avec moins de 0,25 ha mis en valeur au cours d'une campagne agricole.

\section{Systèmes de cultures intégrant le gombo}

Le gombo intervient dans cinq différents systèmes de cultures dans la région de Bouaké : jardins de case, système de culture à base d'igname, système de culture à base de céréales (maïs), système de culture à base de cultures maraîchères et monoculture du gombo. Les jardins de case se rencontrent autour des lieux d'habitation dans les quartiers périphériques. Dans ces jardins de case, la variété Koto se cultive en association avec d'autres cultures : tomate, aubergines, corète potagère, manioc, igname, riz, maïs, etc. (Figure 5). Le gombo récolté est généralement destiné à la consommation directe et le surplus à la vente (surtout pour les étudiants). Ce système se pratique par le deuxième groupe de paysans établi par l'AFCM.

Le système de culture du gombo à base d'igname, que l'on retrouve dans le troisième groupe obtenu avec l'AFCM, fait intervenir l'association du gombo (variété Tomi) à la culture d'igname dans la zone périurbaine de Bouaké (Figure 6). Dans ce système le plus répandu, le champ d'igname appartient à l'homme et la variété Tomi à la femme. Le gombo récolté est destiné à l'autoconsommation et le surplus à la vente. Dans le système de culture du gombo à base de céréales (maïs) pratiqué aussi par le deuxième groupe de producteurs établi par l'AFCM, les pieds de gombo sont présents sur les mêmes planches que ceux du maïs. Dans le système de culture à base de cultures maraîchères pratiqué dans les bas-fonds en ville (Dougouba, Odienné-Kourani, etc.), les producteurs, généralement des allochtones ou des étrangers, cultivent les légumes toute l'année. Dans ce système, la variété Koto est 
cultivée soit sur des planches disposées à côté d'autres planches de légumes (laitue, chou, carotte, etc.) ou bien les pieds de gombo sont sur les mêmes planches que ceux d'autres cultures. Ce système se retrouve dans le premier groupe établi par l'AFCM. La monoculture du gombo pratiquée généralement par les femmes autochtones Baoulé des villages environnants de Bouaké, consiste à cultiver seulement le gombo (variété Tomi), en saison des pluies, sur des petites parcelles $\left(100\right.$ à $\left.200 \mathrm{~m}^{2}\right)$ situées non loin de celles de l'igname. Le gombo produit est vendu dans le but d'avoir des revenus. Ce système se rencontre dans le deuxième groupe de maraîchers obtenu avec l'AFCM.

\section{Itinéraire technique suivi par les producteurs du gombo \\ Dans les jardins de case, les systèmes à} base d'igname ou de céréales, il n'y a pas un itinéraire propre à la culture du gombo. Les pratiques culturales (labour, sarclage, protection phytosanitaire) du gombo en général sont celles de la culture principale. Dans le système de culture à base de cultures maraîchères, les paysans sèment le gombo (variété Koto) sur des planches et démarient à deux plants par poquet. Ils désherbent manuellement. Les doses d'engrais appliquées varient d'un paysan à l'autre et la matière organique n'est généralement pas compostée avant son application. Pour la culture en saison sèche, les eaux usées provenant des bas-fonds insalubres qui jalonnent les ruisseaux de la ville, sont utilisées pour l'arrosage du gombo. La lutte contre les ravageurs des cultures est diversement pratiquée par les producteurs du gombo. L'enquête a révélé que $57 \%$ des producteurs urbains (maraîchers professionnels) pratiquent un traitement phytosanitaire contre les insectes, et $43 \%$ n'en pratiquaient aucun faute de moyen financier. Plus d'une vingtaine de pesticides homologués ou non en maraîchage ont été recensés comme insecticides pour les traitements phytosanitaires qui sont fréquents pendant le cycle cultural du gombo (au moins 2 fois par semaine par $63 \%$ des maraîchers urbains qui pratiquent les traitements). La variété Tomi est populaire auprès des autochtones Baoulé qui la cultivent dans les champs d'igname. Elle est tardive (100 à 110 jours pour réaliser la première récolte) et moins sujette aux attaques de maladies et d'insectes ravageurs. Par contre, la variété Koto est la plus cultivée par les populations allochtones et étrangères. Elle est précoce (60 à 70 jours pour effectuer la première récolte) avec un cycle de production plus courte (1 à 2 mois). Elle est sensible aux maladies et fortement attaquée par les insectes, ce qui explique les fréquents traitements phytosanitaires pratiqués par certains producteurs.

\section{Synthèse de la typologie des producteurs maraîchers selon l'Analyse Factorielle en Composante Multiple (AFCM)}

La Figure 4 présentant les résultats de l'AFCM, indique que les maraîchers interrogés se répartissent en trois grands groupes selon la variété de gombo cultivée, le sexe, les origines, la profession principale, la maîtrise des techniques culturales, etc. Le premier groupe est constitué par les maraîchers professionnels originaires du Mali, du Burkina Faso et du Togo. Agés de 41 à 60 ans, ils sont mariés et possèdent une grande famille (plus de 13 enfants). Installés dans les zones de bas fonds ou autres sites non bâtis de la ville sans un contrat d'exploitation, ils cultivent principalement le gombo (variété Koto) sur de petites superficies en monoculture (environ $100 \mathrm{~m}^{2}$ ) pour des revenus monétaires. Ils bénéficient de la visite des agents de la vulgarisation agricole (ANADER). Ils emploient les engrais dans leur champ. En plus des problèmes de commercialisation, ces producteurs sont régulièrement exposés à des expulsions par la municipalité ou autres propriétaires. Le deuxième groupe est composé par les maraîchers professionnels originaires du Nord de la Côte d'Ivoire. Ces producteurs habitent en ville ou dans les quartiers périphériques de Bouaké (Tchèlèkro, Kotiakro, Piscine, etc.). Agés de 23 à 40 ans, ils sont illettrés, de 
niveau primaire ou secondaire. Ils cultivent le gombo (variété Koto) et autres légumes toute l'année sur des parcelles (moins de 0,25 ha) situées dans les zones périurbaines pour l'autoconsommation et de l'argent. Les familles sont de taille moyenne (6 à 10 enfants). Ils exploitent de façon continue les mêmes parcelles pendant plusieurs années, pour des raisons de difficultés d'acquérir de nouveaux sites (un producteur a affirmé au cours de l'enquête qu'il exploite son site d'environ $2000 \quad \mathrm{~m}^{2}$, depuis 1959). L'acquisition des parcelles exploitées se fait sous forme d'entente mutuelle où le producteur offre des dons (bouteilles de gin, produits de récolte, participation à des cérémonies funéraires, etc.) au propriétaire terrien. Le dernier groupe est formé par les autochtones Baoulé de Bouaké. Il comprend des étudiants et des producteurs âgés de plus de 60 ans. Ils cultivent le gombo (variété Tomi) en plein champ en saison des pluies sur de petites superficies ou dans les champs d'igname. Ces producteurs n'ont signalé aucun problème foncier.

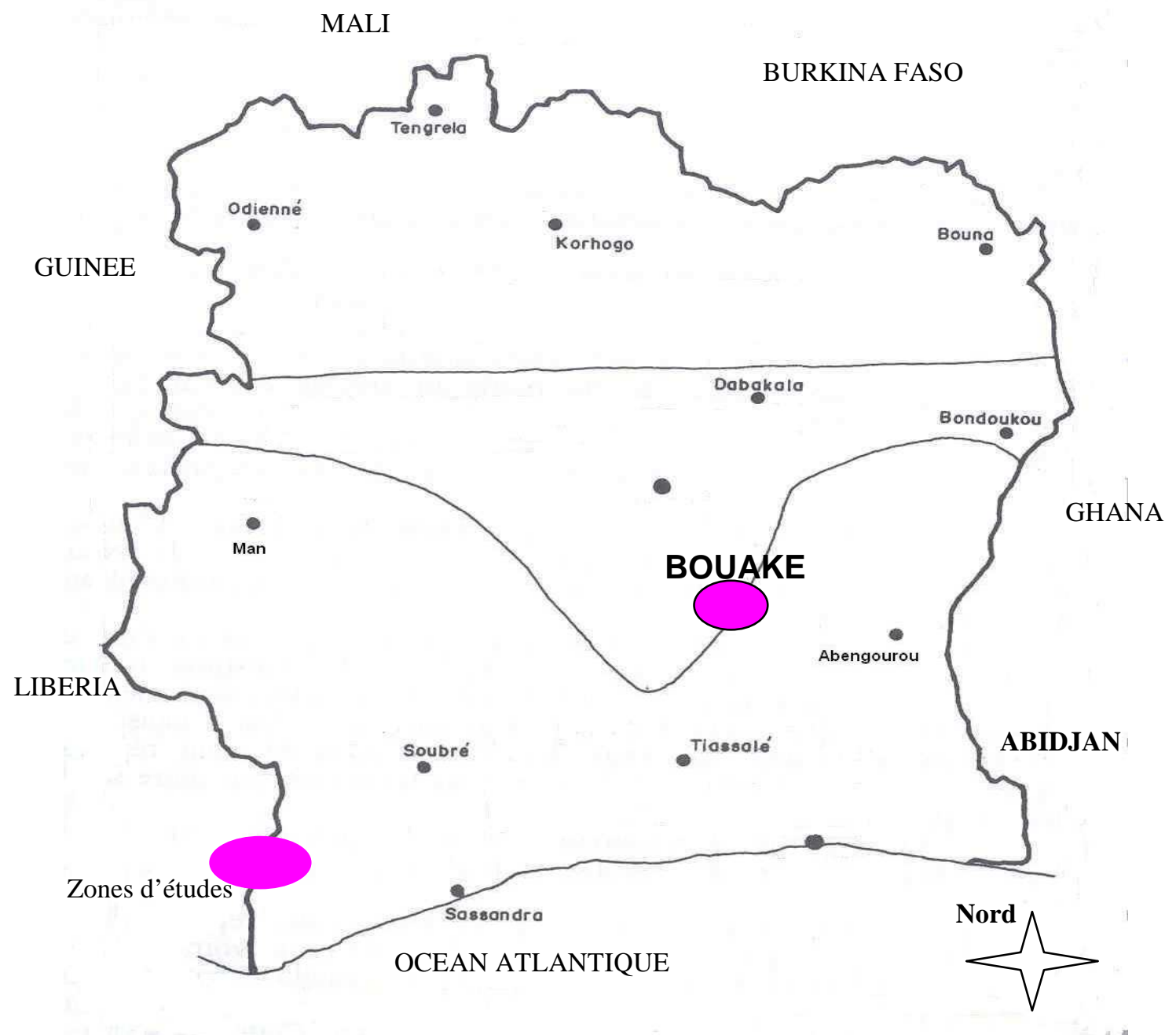

Figure 1 : Situation géographique de Bouaké, au Centre de la Côte d'Ivoire. Echelle : $1 / 4000000$ 


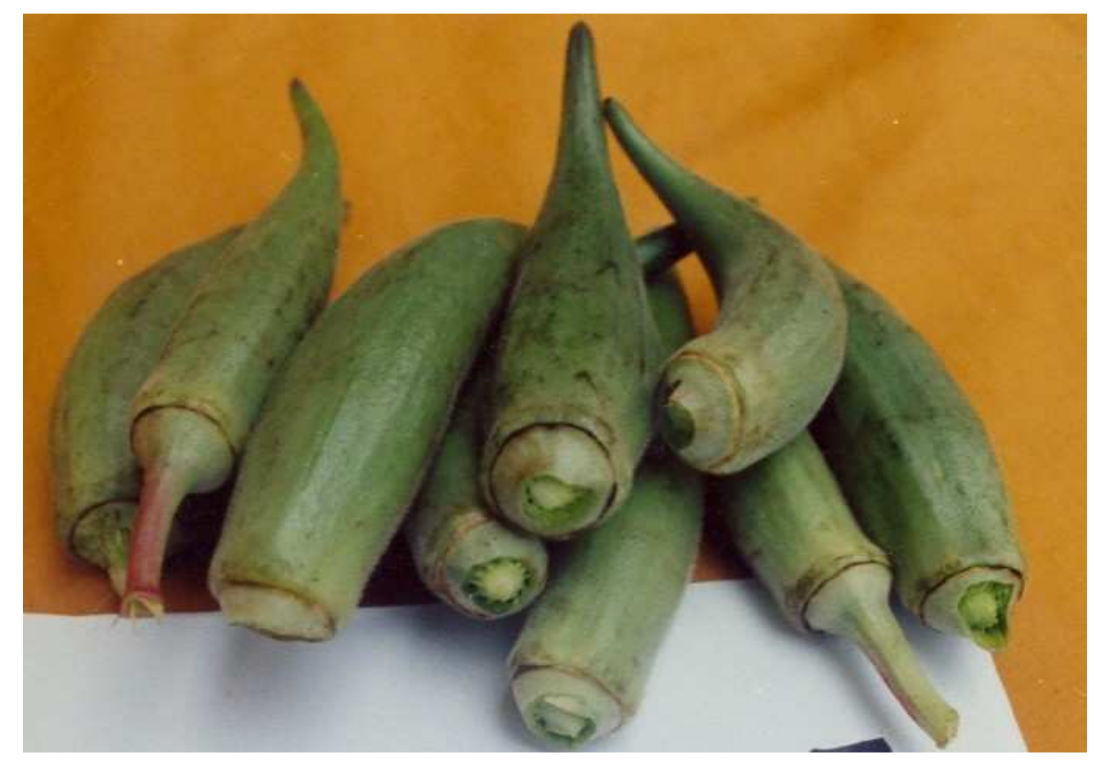

Figure 2 : Fruits du gombo de la variété Tomi (Abelmoschus caillei).

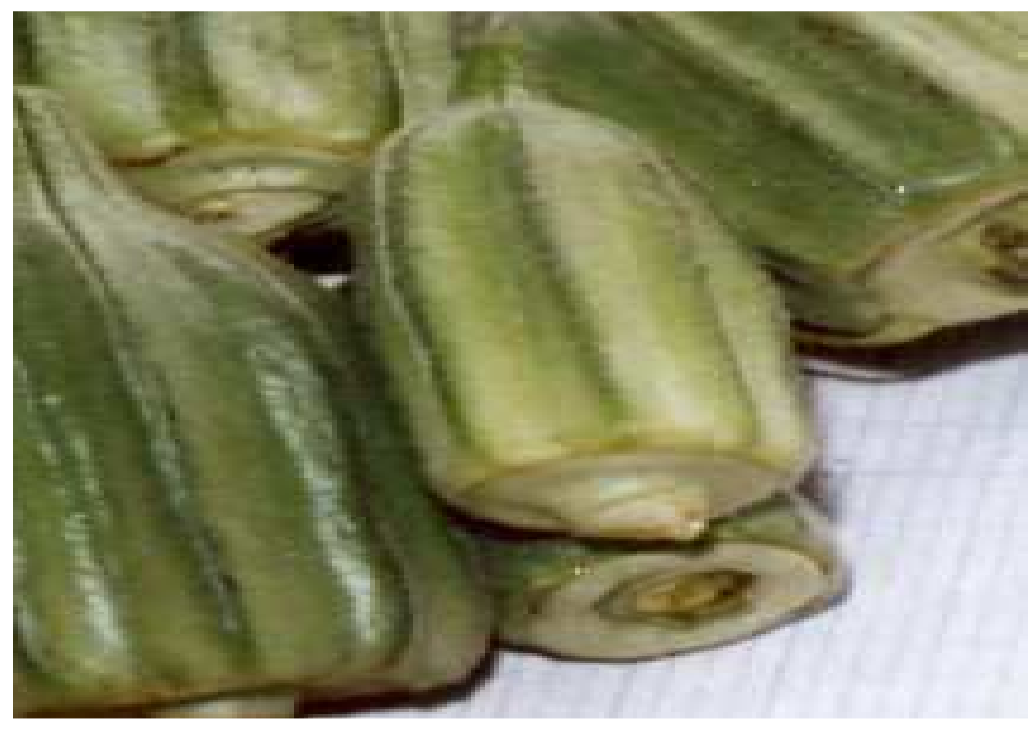

Figure 3 : Fruits du gombo de la variété Koto (Abelmoschus esculentus) 


\section{PLAN 13}

MODALITES ACTIVES ${ }^{(1)} 51$

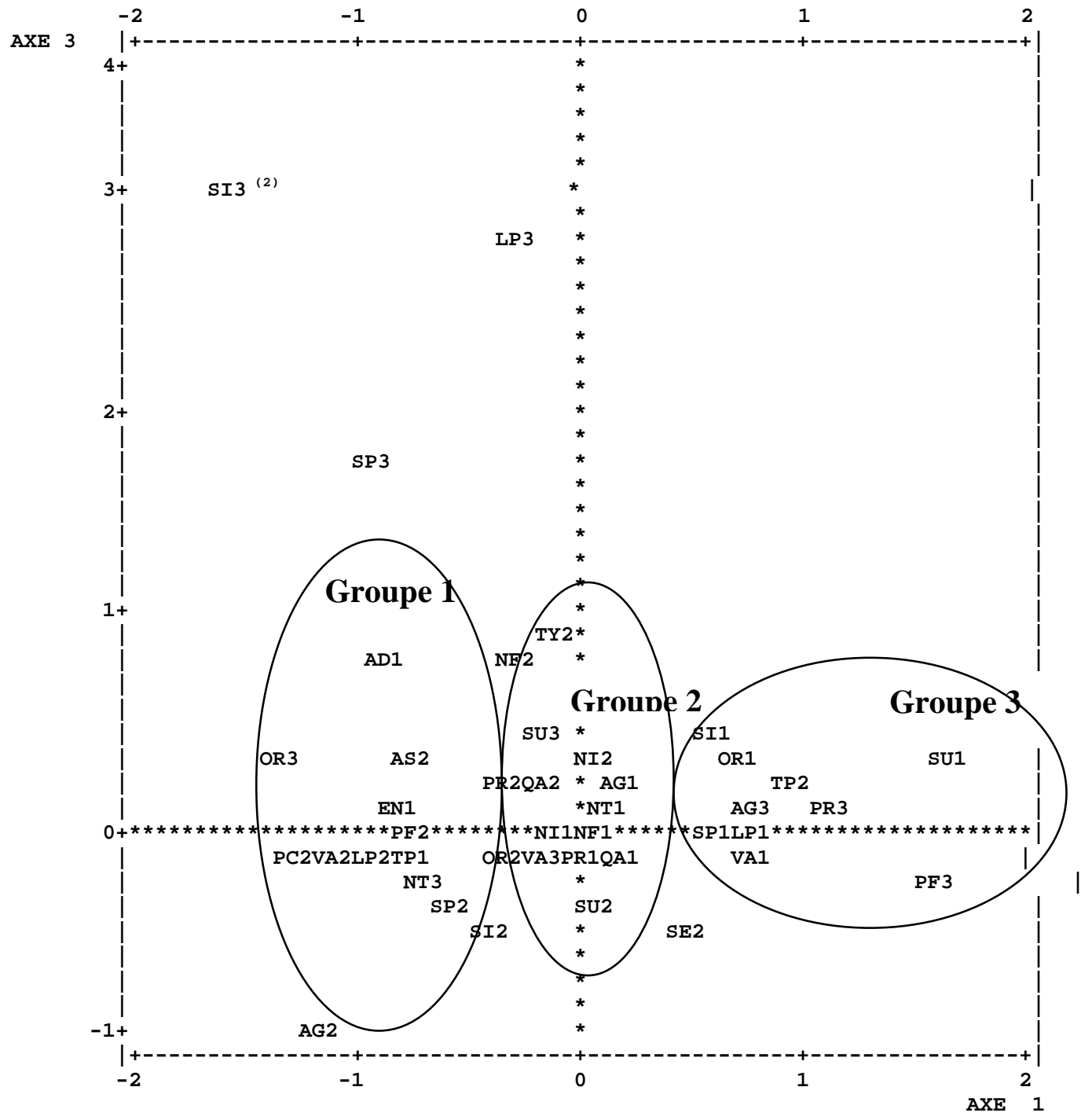

Figure 4 : Typologie des paysans enquêtés selon l'AFCM.

Groupe 1: Maraîchers d'origine étrangère (Mali, Burkina Faso, Togo), producteurs de gombo de type Koto, exposés à des problèmes fonciers

Groupe 2: Maraîchers professionnels originaires du Nord de la Côte d'Ivoire, producteurs du gombo de type Koto et autres légumes, accès difficile à de nouveaux sites de production

Groupe 3: Maraîchers, autochtones Baoulé de Bouaké, producteurs de gombo de type Tomi en plein champ, aucun problème foncier

(1) Les modalités actives sont celles qui ont contribué à la construction des axes principaux dans le plan 1 et 3 . Ce sont les plans 1 et 3 qui contenaient le plus d'information.

(2) Les modalités excentrées SI3, SP3, LP3 renvoient à un individu qui ne s'est pas prononcé sur sa situation matrimoniale (SI3), superficie du gombo>1,25 ha (SP3). Ces variables ont été prises comme éléments supplémentaires qui n'ont été pris en compte dans le calcul des axes.

\section{Légende des modalités}

OR1 : origine 1 (autochtones), OR2 : Allochtones, OR3: Etrangers, N11: niveau scolarité (primaire), NI2: secondaire, NI3: Supérieur, SE1 : sexe 1 (homme), SE2 : femme; AG1 : Age $1: 23-40$ ans, AG2 : 40-60 ans, AG3 :>60 ans, SU1 : superficie exploitation $1<0,25$ ha; SU2 : surface exploitation $2: 0,25<$ surface exploitation $<3$ ha 
TP1: Type d'exploitation : familiale TP2: type d'exploitation : collective SI1: célibataire, SI2: marié; SI3 : sans réponse, $\mathrm{PF} 1$ : sans problème foncier, $\mathrm{PF} 2$ : problème foncier modéré, $\mathrm{PF} 3$ : problème foncier,

SP1 : superficie du gombo $<0,25$ ha ; SP2 : 0,25 ha $<$ superficie gombo $<1,25$ ha ; SP3 : superficie gombo $>1,25$ ha,

AS1 : association gombo à d'autres cultures; AS2 :pas d'association du gombo à d'autres cultures; AS3 : sans réponse ; EN1 :pas d'engrais; EN2 :oui engrais; EN3 :sans réponse ; PC1 : autoconsommation du gombo ; PC2 : culture du gombo pour la vente ; PC3 :culture du gombo pour autoconsommation et vente; PC4: sans réponse; NF1 :culture du gombo 1 fois/an ; NF1 :culture du gombo 2 fois/an; PR1 :paysan; PR2 :salarié ; PR3 :profession libérale ; PR4 : sans profession ; PR5 : sans réponse; PR6 :étudiant; QA1 :habite un quartier de Bouaké ; QA2 : habite un quartier environnant ; QA3 :sans réponse ; VA1 : cultive Tomi ; VA2 : cultive Koto ; VA3 : cultive Tomi et Koto ; VA4 :sans réponse; LP1 : culture en plein champ ; LP2 : culture dans bas-fonds ; LP3 :Sans réponse; TY1 :arrosage manuel ; TY2 : utilisation de motopompe.

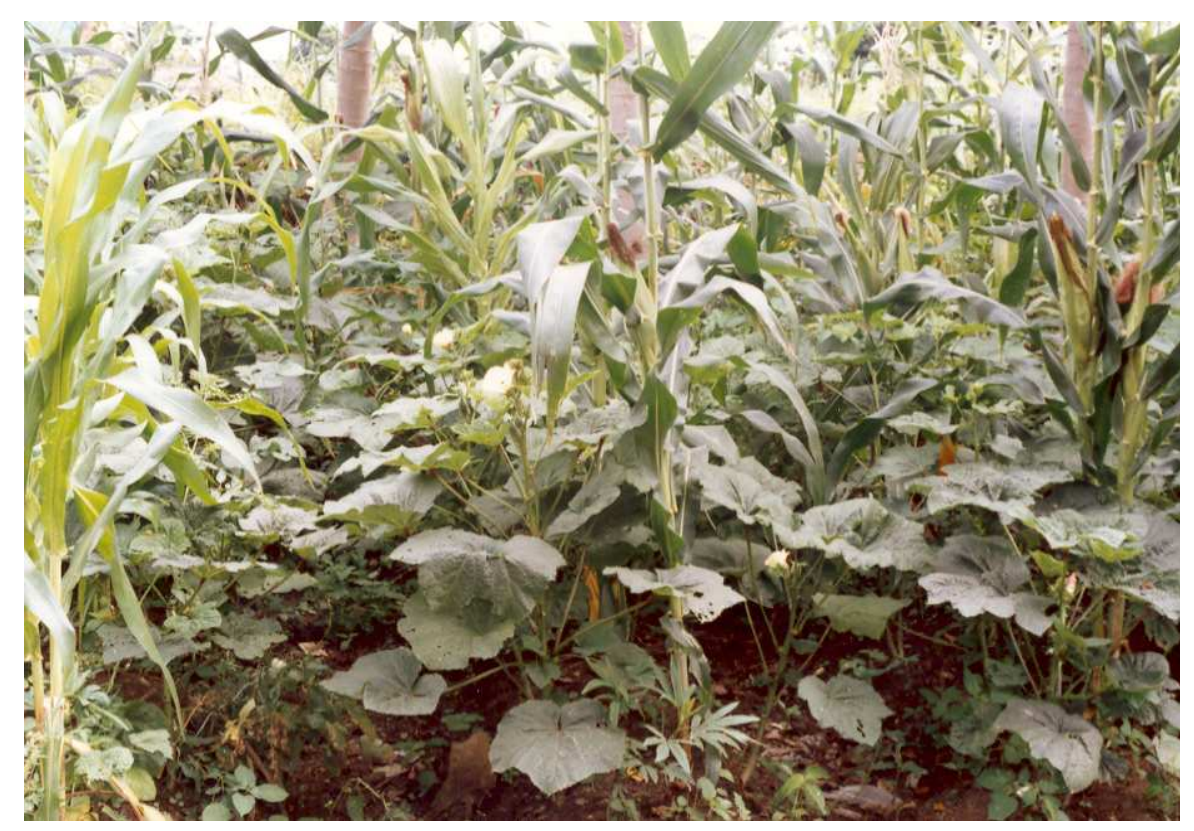

Figure 5: Association gombo et maïs dans un jardin de case près de Bouaké.

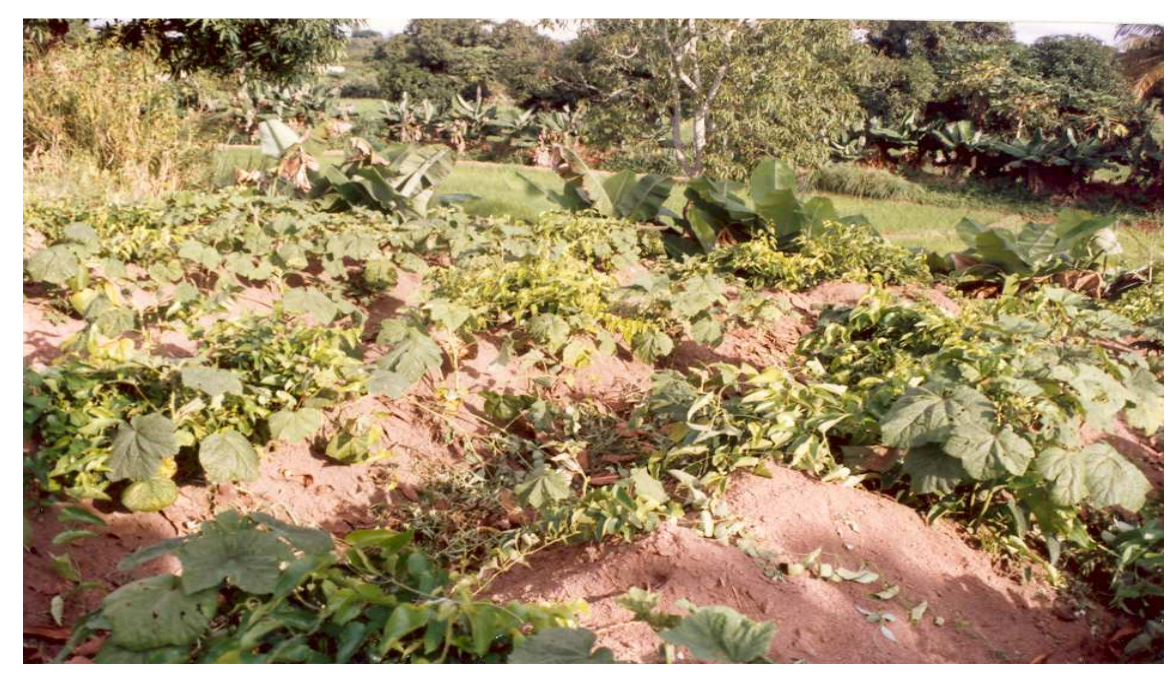

Figure 6 : Association gombo et igname dans un champ situé à l’Ouest de Bouaké. 
Tableau 1: Caractérisation sociologique des producteurs maraîchers rencontrés dans la zone urbaine et périurbaine de Bouaké, en 2001.

\begin{tabular}{lc}
\hline Caractères sociologiques & Pourcentage (\%) de populations \\
\hline Sexe & 74 \\
Homme & 26 \\
Femme & 33 \\
\hline Origine & 64 \\
Autochtones & 3 \\
Allogènes & \\
Etrangers & 64 \\
\hline Age & 31 \\
23 à 40 & 5 \\
41 à 60 & \\
61 à 71 & 53 \\
\hline Situation matrimoniale & 44 \\
Mariés & 3 \\
Célibataires & \\
Refus de se prononcer & 47 \\
\hline Nombre d'enfants dans la famille & 41 \\
0 à 5 & 12 \\
6 à 10 & 68 \\
11 à 24 & 18 \\
\hline Niveaux d'études & 8 \\
Illettré & 6 \\
Primaire & \\
Secondaire & 57 \\
Supérieur & 40 \\
\hline Lieu d'habitation & 3 \\
Quartiers périphériques & 65 \\
Villages & \\
Centre ville & \\
\hline Activité principale & \\
Maraîchage toute l'année & \\
Salariés du privé ou public & \\
Profession libérale (mécanicien, etc.) & \\
Etudiants & \\
\hline & \\
\hline &
\end{tabular}

\section{DISCUSSION}

Typologie des producteurs de gombo

La forte implication des allochtones et la présence de quelques étrangers dans le maraîchage urbain de Bouaké peuvent s'expliquer par l'absence d'emploi dans d'autres domaines d'activités, car ces agents économiques viennent en ville pour chercher du travail autre que celui de la terre. A ce sujet, Kêdowidé et al. (2010) ont noté qu'à Ouagadougou (Burkina Faso), l'activité maraîchère est dominée par des personnes issues de l'exode rural et ne disposant pas d'autres qualifications pour effectuer une autre activité professionnelle. Diao (2004) avait relevé la forte présence des migrants 
Guinéens dans le maraîchage urbain de Dakar qu'il avait expliqué par la facilité d'accès à un emploi. De même, la forte présence de toutes les catégories socio-professionnelles (salariés des secteurs publics et privés, professions libérales, jeunes, hommes, personnes âgées, etc.) dans le maraîchage est aussi liée aux opportunités de sources de revenus qu'offre cette activité aux populations urbaines de Bouaké. A cet effet, Assouma et al. (2008) ont montré que pour compléter leurs revenus, des agents de diverses professions (vigiles, détaillants, employés de magasin, chauffeurs, fleuristes, réparateurs de radio, etc.) avaient adopté le maraîchage dans les zones urbaines d'Abidjan et de Yamoussoukro en Côte d'Ivoire. Pour Nguegang (2008), la forte augmentation du nombre de maraîchers urbains à Yaoundé au Cameroun à partir de 1992 est liée à la crise économique des années 1990 qui a contraint de nombreux travailleurs au chômage et réduit les offres d'emplois. Pour survivre, ces personnes se sont donc converties au maraîchage. Les problèmes fonciers rencontrés par les maraîchers allochtones et étrangers peuvent être dus au manque de parcelle cultivable dans les zones urbaines. Les plans d'urbanisation ne prévoient pas généralement de place pour l'agriculture. Selon Diao (2004), ce problème foncier constitue un frein à tout investissement dans le secteur maraîcher par les producteurs de légumes à Dakar.

Cette analyse confirme le rôle important joué par le maraîchage dans la génération de revenu par sa capacité de création d'emploi pour les populations urbaines aussi bien en Côte d'Ivoire qu'ailleurs en Afrique. Mais, le plus grand obstacle au développement de cette agriculture semble être celui du foncier qui n'est pas toujours disponible pour les acteurs. Dans un contexte de lutte contre la pauvreté en Afrique, la prise en compte de l'agriculture dans les plans d'urbanisation des villes africaines pourrait être une solution.
Systèmes de cultures intégrant le gombo dans la Commune de Bouaké

$\mathrm{La}$ domination de l'association $\mathrm{du}$ gombo aux autres spéculations peut s'expliquer par le fait que le gombo n'est pas considéré comme une culture principale dans les systèmes de culture par les producteurs de Bouaké. Il est produit en marge des autres cultures. Mais, cette pratique ne semble pas être générale en Côte d'Ivoire car Kouakou et al. (2010) ont montré dans une étude sur les activités agro-pastorales à Yopougon, une Commune d'Abidjan, que le gombo (Abelmoschus esculentus) était l'espèce marâ̂chère la plus cultivée à cause de son cycle court et de la possibilité d'être récolté d'au moins 2 fois par semaines pendant 2 ou 3 mois. Selon les auteurs précités, la production de cultures de cycles courts comme le gombo (Abelmoschus esculentus), permet aux paysans de palier la réduction de superficie et de satisfaire leurs besoins d'urgence de ménages.

Par ailleurs, la faible présence du service de vulgarisation agricole sur le terrain peut être liée au manque de moyen dont dispose cette structure (ANADER) pour assurer sa mission. Le renforcement des capacités de la vulgarisation agricole peut faciliter le transfert en milieu paysan des technologies mises au point par la recherche. En effet, pour accroître la productivité du gombo, des techniques améliorées de production du gombo portant sur les densités, les périodes de semis, les régimes de fertilisation et d'arrosage ont été élaborées par la recherche agronomique (Fondio et al., 1999 ; Fondio et al., 2003; Fondio, 2005). Mais ces techniques ne sont pas mises en œuvre par les producteurs à cause de leur faible diffusion auprès des utilisateurs finaux (paysans).

Ici, il ressort donc que la production du gombo est dominée dans les zones urbaines de Bouaké par son association avec les autres cultures. Cependant, le faible appui du service de vulgarisation agricole aux producteurs 
serait le principal facteur limitant l'adoption par les paysans des technologies mises au point par la recherche agronomique en Côte d'Ivoire. Pour ce faire, une meilleure coordination entre la recherche et la vulgarisation agricole à travers une démarche participative impliquant les producteurs pourrait contribuer à améliorer les systèmes de productions maraîchères dans la région de Bouaké.

\section{Conclusion}

La caractérisation des systèmes de culture du gombo dans le maraîchage de Bouaké indique que la production du gombo est assurée par les allochtones (64\%), les autochtones $(33 \%)$ et les étrangers $(3 \%)$ issus de diverses couches socio-professionnelles. Elle est dominée par l'association culturale du gombo avec les autres cultures. Les producteurs allochtones et étrangers sont confrontés à des problèmes fonciers qui constituent le principal facteur au développement de leurs activités. En outre, le faible encadrement des producteurs par la structure nationale de la vulgarisation agricole sur le terrain semble limiter la diffusion des technologies mises au point par la recherche agronomique.

Pour améliorer la productivité du gombo, il serait indiqué de faciliter l'accès des maraîchers à la terre par l'adoption d'une politique d'urbanisation favorable à l'intégration des espaces urbains réservés à la pratique agricole dans les villes. En outre le renforcement des capacités de la vulgarisation agricole et l'adoption d'une recherche participative impliquant la recherche, les vulgariseurs et les producteurs faciliteraient la diffusion des technologies mises au point par la recherche agronomique.

\section{REFERENCES}

Affou YS. 1999. Agriculture intra-urbaine en Côte d'Ivoire : les cultures et les acteurs. In Agriculture Périurbaine en Afrique Subsaharienne, Moustier P, Mbaye A, De
Bon $\mathrm{H}$ (eds.). CIRAD Editions : Montpellier ; 101-111.

Ahoussou N, Koffi G, Sangaré A. 1995. Côte d'Ivoire: rapport de pays pour la conférence technique internationale de la FAO sur les ressources phylogénétiques. Abidjan, p.75.

ANADER. 2001. Rapport d'activités 2000. Direction Régionale de l'Agence Nationale d'Appui au Développement Rural (ANADER) de Bouaké. Bouaké, p.112.

Assouma Y, Allah F, Djidji AH, Fondio L, Mahyao A, Kouamé C. 2008. Enquête sur la production et la commercialisation des légumes traditionnels dans les zones urbaines et périurbaines d'Abidjan et de Yamoussoukro en Côte d'Ivoire. Rapport, CNRA/Projet IndigenoVeg. CNRA, Bouaké, p.16.

Diao MB. 2004. Situation et contraintes des systèmes urbains et périurbains de production horticole et animale dans la région de Dakar. Cah. Agric., 13(1): 3949.

DSDI. 2005. Annuaire des Statistiques Agricoles. Les Séries Stat'Agri. Direction des Statistiques et de la Documentation (DSDI). Ministère d'Etat, Ministère de l'Agriculture. RCI. Abidjan, p.100.

Fondio L, Kouamé C, Traoré D, Djidji AH. 1999. Densités de semis, croissance et production de deux lignées de gombo (Abelmoschus spp.) en Côte d'Ivoire. Cah. Agric., 8(5): 413-415.

Fondio L, Djidji AH, Kouame C, Traore D. 2003. Effet de la date de semis sur la production du gombo (Abelmoschus spp.) dans le Centre de la Côte d'Ivoire. Agron. Afr., 15(1):1-50.

Fondio L. 2005. Contribution au développement du gombo dans le Centre de la Côte d'Ivoire: analyse socioéconomique et amélioration de la productivité de la variété Tomi (Abelmoschus caillei (A. Chev.) Stevels), par l'arrosage et la fertilisation, selon les 
périodes de semis. Thèse de Doctorat Unique, UFR/Biosciences, Université de Cocody-Abidjan, Abidjan, p.162.

Kêdowidé CMG, Sedogo MP, Cissé G. 2010. Dynamique spatio temporelle de l'agriculture urbaine à Ouagadougou : Cas du maraîchage comme une activité montante de stratégie de survie. VertigO la revue électronique en sciences de l'environnement, 10(2) [En ligne] (URL : http://vertigo.revues.org/10312).

Kouakou YE, Koné B, Bonfoh B, Kientga S M, N'Go YA, Savane I Cissé G.2010. L'étalement urbain au péril des activités agro-pastorales à Abidjan. VertigO - La Revue Electronique en Sciences de l'Environnement, 10(2), [En ligne] (URL : http://vertigo.revues.org/ 10066).

Foucher JF. 1992. Logiciel de dépouillement d'enquête sur micro-ordinateur. Service Central Informatique du CIRAD/ GERDAT, Montpellier; p.181.

Nguegang AP. 2008. l'agriculture urbaine et périurbaine à Yaoundé : analyse multifonctionnelle d'une activité montante en économie de survie. Thèse de Doctorat en Sciences Agronomiques et ingéniérie Biologique, Université Libre de Bruxelles, Bruxelles, p.200.

Stevels JMC. 1990. Légumes traditionnels du Cameroun, une étude agro botanique. Wageningen, Pays-Bas: Wageningen Agricultural University Papers, N90-1, p.262. 